\title{
The vertical patterns of distribution and diversity on a sheltered rocky shore in North Wales
}

Volume 4 Issue 5 - 2016

\section{Introduction}

The aim of this practical was to examine the percentage cover of different algae on the upper, middle and lower shore of a rocky shore in North Wales, and determine the mean, standard deviation and standard error of the results. At Meani Strait Bangor North Wales the intertidal algae form a characteristic of horizontal zones, which presents the changes between high shore habitat, mid-shore habitat and the low shore habitats. Pelveria canaliculata covers the largest percentage of higher shore. Exposed to high winds and air that can last days at a time, and may not be covered by water for just as long if not longer. Fucus spiralis also is found in the higher shore but very little, and is buried under the Pelveria canaliculata so therefore is not exposed to as such extreme environments. Fucus spiralis is also found on the mid-shore, covering again a small percentage. However here the alga is in better conditions. There is a lot more coverage by water therefore reducing the access of wind and cold air to the algae. The dominating algae on the mid-shore however is Fucus vesiculosus covering well over $70 \%$ of the mid-shore. This dominant algae also makes its way down to the lower shore stretching across the horizontal zones of the mid and lower shores, where it meets Ascophyllum nodosum, this algae is the most dominant of all the plants found on this shore. Reaching as much as $98 \%$ coverage along the horizontal zone of the lower shore. Therefore showing that species is determined largely by its ability to tolerate prolonged desiccation during tidal exposure [1]. We then measured 5 different algae fonds in the $100 \mathrm{~cm}$ quadrate area, to get the mean length. And also took note of any creatures that where found living amongst the algae. For example Carcinus maenus (common shore crab).

\section{Materials \& method}

\section{Study Location}

The data for this publication was collected on Ynys Faelog, one of the many sheltered rocky shores of the Menai Straits, separating Anglesey from the Welsh mainland. The boundaries between low and high shore were calculated using the woody-cross-stick-thing-device, showing a distance of $2.0 \mathrm{~m}$ between the start of the high shore, and the end of the low shore.

\section{Evaluating the productivity of algal species from low to high shore}

The biomass of algal species was examined in order to test the hypothesis that productivity changes between the shore zones. Shore zones were estimated from the identification of the dominant algal species, after which, five quadrats (measuring $0.5 \mathrm{~m} 2$ ) were placed randomly in each shore zone; high; mid; and low. In each quadrat, the percentage cover of canopy species was recorded. The canopy organisms were then lifted, allowing for the identification of smaller species, and for the more accurate estimation of total percentage cover of canopy species.

\author{
Jennah Williams \\ Department of Marine Biology, Bangor University, USA
}

Correspondence: Jennah Williams, Department of Marine Biology, Bangor University, 442I Mariannes Ridge Rd Charlotte NC 28273, USA, Tel 7046I21880,

Email jennahrwilliams9I@hotmail.co.uk

Received: November 02, 2015 | Published: November 16, 2016

\section{Evaluating the competitive ability of algal species from low to high shore}

The average frond height has been used as an indicator for the competitive ability of each species. Taller plants would be assumed to have a greater competitive advantage over the smaller species. In each quadrate, the five largest fronds were identified, measured, and their height recorded in centimetres. This was done on each of the five quadrates, and for each of the shore zones, allowing the competitive ability of species on different shore zones to be compared.

\section{Evaluating the severity of environmental conditions from low to high shore}

The severity of environmental conditions was assessed through the diversity of species. The figures from each shore zone were compared. High species diversity suggests favourable environmental conditions. Following each quadrat, on each of the three shore zones, species counts were taken; in finding as many species as possible, with only a time limit of 300 seconds, the diversity on each of the shore zones can be estimated.

\section{Results}

\section{Evaluating the productivity of algal species from low to high shore}

The average Total percentage cover of algae on the high shore was the lowest with the highest average percentage cover found on the low shore. In the sample area it was discovered that Pelvitia canaliculatais the dominant species, and had the highest abundance of any algae on the high shore, with Fucus spiralis as the second most dominant species.

However it can be seen from the standard error bars that other sampling areas on the high shore may have equal abundances of Pelvitia \& F. Spiralis. In the mid shore there is no Pelvitiaor F. 
spiralisbut unlike the high shore there is a high abundance of $F$. Vesiculosis, the dominant species, and significant amounts of Ascophyllum nodosum. The standard error bars on the mid shore graph show that it would be very unlikely to find equal amounts of $F$. Vesiculosis \& Ascophyllumnodosum any where on the Ynys faelog mid shore.

\section{Evaluating the severity of environmental conditions from low to high shore}

The total number of species over all three zones is very similar. The highest number of species was found on the low shore $(4+/-1.3$, Figure 1). In comparison, the lowest number of species was found on the high shore $(3.6+/-0.68$, Figure 1$)$.

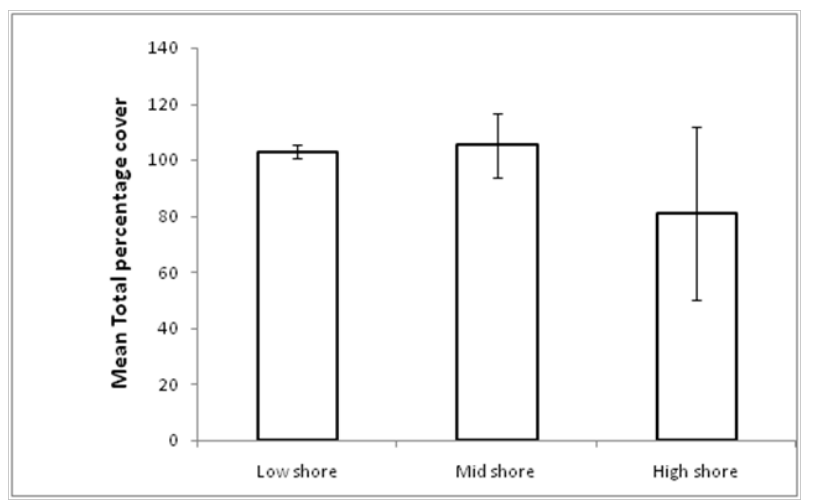

Figure I Mean total percentage algal cover on the different shore levels of Ynys Faelog.

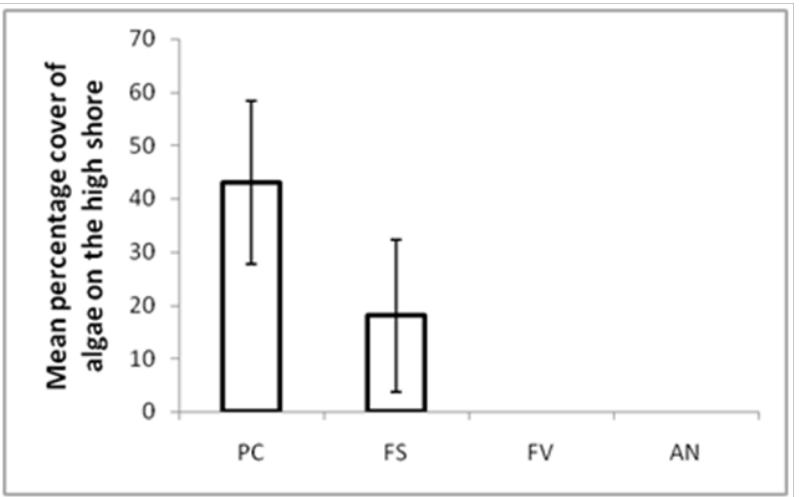

Figure 2 Mean percentage coverage of $P$. canaliculata and F. spiralis on the low shore of Ynys Faelog. The standard deviations of P. canaliculata and F. spiralis are 15.3 and 14.4 respectively.

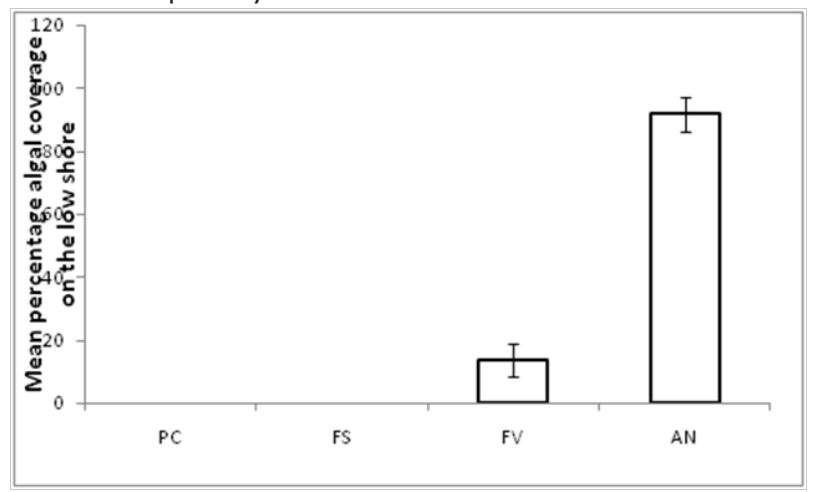

Figure 3 The mean percentage of coverage of $F$. vesiculosis and A. nodosum on the mid shore of Ynys Faelog. The standard deviations of $F$. vesiculosis and $A$. nodosum are 12.2 and II.6 respectively.

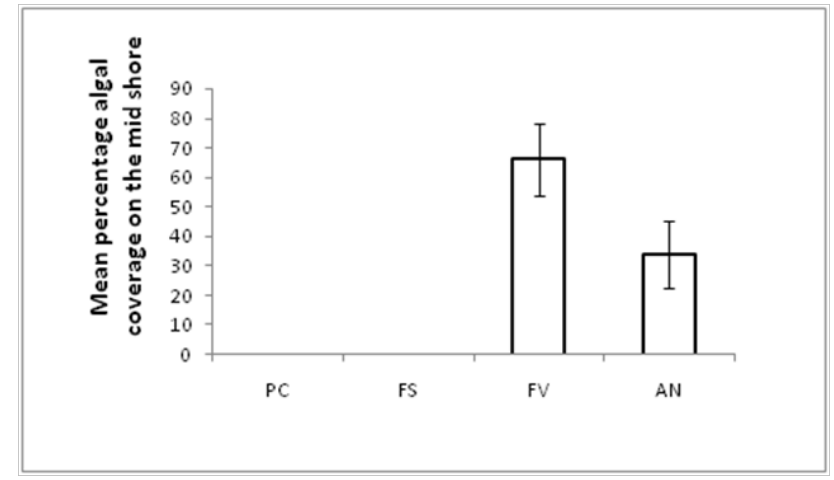

Figure 4 The mean percentage coverage of $F$. vesiculosis and A. nodosum on the low shore of Ynys Faelog. The standard deviations of $F$. vesiculosis and $A$. nodosum are 5.3 and 5.7 respectively.

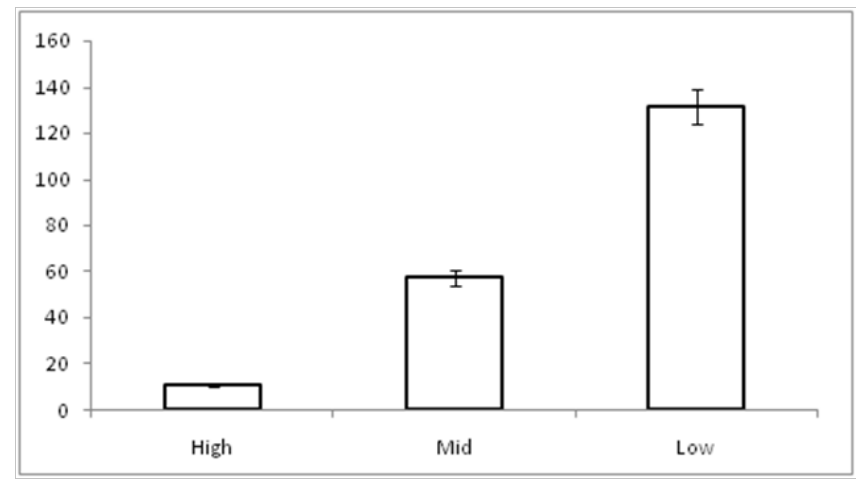

Figure 5 Comparison maximum height of the species across different shore zones.

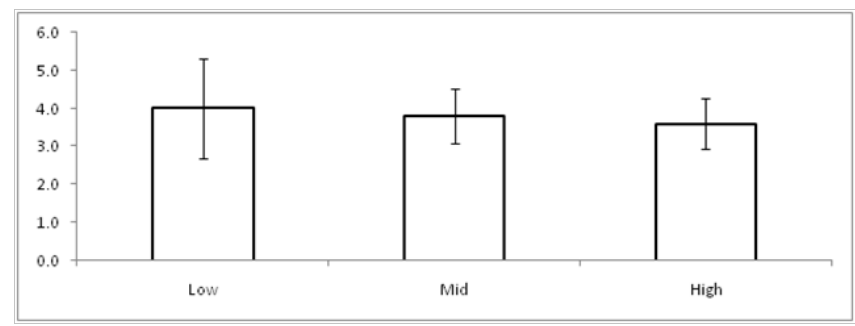

Figure 6 The mean total number of species in the different shore zones.

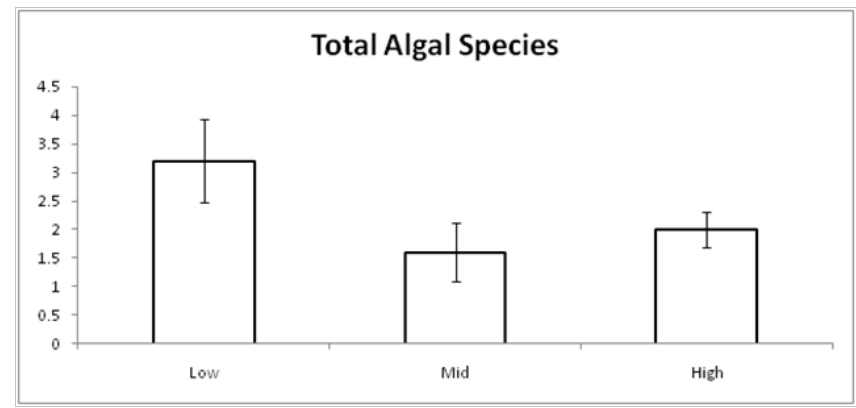

Figure 7 Total Algal Species.

\section{Discussion}

The results of this experiment show that the lower shore habitat is the best for species to grow on. The living conditions for algae such as Ascophyllum nodosum are ideal. There are plenty of nutrients within the water and muddy sediment. Also as the muddy sediment was a light in colour it shows that the sediment is well oxygenated, providing oxygen for the algae, therefore providing the right 
conditions for photosynthesis to take place. There was no muddy sediment on the higher shore, showing that the algae on that part of the shore do not have as much nutrients as the algae on the lower shore. This experiment also shows that one type of algae is not restricted to a certain part of the rocky shore. It can spread out along the horizontal zones of the shore. Also this experiment shows the reproduction rate of the algae, showing which is the most dominant by the percentage cover, within the rocky shore. Fucus spiralis seemed to be the most dominant on the higher and mid-shore. Not only does Fucus spiralis grow much faster in length then Pelveria canaliculata, but as it has a longer reproductive stage it outgrows and out populates the Pelveria canaliculata, as a result of this microscopic Pelveria only grows where the Fucus spiralis has been removed, either by humans or natural causes i.e. the tide.

The graphs and tables provide a visual understanding of the dominance of the algae on the lower shore for Ascophyllum nodosum and also provide a visual understanding of the difference in habitat population across the shore zones. In conclusion, this experiment showed that the population of algae on the lower shore is greater then on the other zones of the shore, due to its nutrients and sheltered conditions, making this the ideal place for algae to grow and reproduce. This experiment also shows, that different algae can survive in different conditions, and adapt over time to cope with stressful conditions and lack of nutrition. And also provides understanding of the different types of algae found on this type of habitat, a rocky shore.

\section{Acknowledgments}

None.

\section{Conflicts of interest}

None.

\section{References}

1. Schonbeck M, Norton TA. Factors controlling the upper limits of fucoid algae on the shore. J Exp Mar Biol Ecol. 1978;31:303-313. 